\title{
PHENOLIC AND STEROLIC PROFILE OF A PHYLLANTHUS AMARUS EXTRACT AND CHARACTERIZATION OF NEWLY SYNTHESIZED SILVER NANOPARTICLES
}

\author{
ANDREIA CORCIOVĂ ${ }^{1 \#}$, CORNELIA MIRCEA ${ }^{1 * *}$, CRISTINA TUCHILUȘ $^{2 \#}$, OANA CIOANCĂ $^{1 \#}$, \\ ANA-FLAVIA BURLEC ${ }^{1 *}$, BIANCA IVĂNESCU ${ }^{1 *}$, LAURIAN VLASE ${ }^{3 *}$, ANA-MARIA GHELDIU ${ }^{3 *}$, \\ ADRIAN FIFERE ${ }^{4 \#}$, ANA-LĂCRĂMIOARA LUNGOCI ${ }^{4 \#}$, MONICA HĂNCIANU ${ }^{1 \#}$ \\ 1"Grigore T. Popa” University of Medicine and Pharmacy, Faculty of Pharmacy, 16 Universității Street, 700115, Iași, Romania \\ 2 "Grigore T. Popa" University of Medicine and Pharmacy, Faculty of Medicine, 16 Universității Street, 700115, Iași, Romania \\ 3 "Iuliu Hațieganu” University of Medicine and Pharmacy, Faculty of Pharmacy, 12 Ion Creangă Street, 400010, Cluj-Napoca, \\ Romania \\ 4 "Petru Poni" Institute of Macromolecular Chemistry, Center of Advanced Research in Bionanoconjugates and Biopolymers, $41 \mathrm{~A}$ \\ Grigore Ghica-Vodă Alley, 700487, Iași, Romania
}

*corresponding author: corneliamircea@yahoo.com

${ }^{\#}$ All authors have equal contribution

Manuscript received: February 2018

\begin{abstract}
The aim of this study was to identify and quantify some biologically active compounds from the Phyllanthus amarus species, followed by the synthesis and characterization of silver nanoparticles. For identification and quantification purposes, different methods were used, such as UV-Vis spectrophotometric methods and HPLC-UV-MS method for polyphenols analysis, LCMS methods for methoxylated flavonoids and phytosterols analysis. After identification, the following compounds were quantified: p-coumaric acid, ferulic acid, isoquercitrin, quercitrin, rutoside, hispidulin, acacetin, casticin, stigmasterol, betasitosterol, and campesterol. To the best of our knowledge, this is the first report on the identification and quantification of hispidulin, casticin, acacetin, and ergosterol in Phyllanthus amarus. Furthermore, the extract was used in order to obtain silver nanoparticles (AgNPs), which were characterized by UV-Vis spectroscopy, FTIR, TEM, EDX. Additionally, the nanoparticles were tested for antimicrobial and antioxidant activities. The results confirmed that Phyllanthus amarus is a source of biological compounds that can be used for nanoparticles synthesis, with potential health use.
\end{abstract}

\section{Rezumat}

Acest studiu a urmărit identificarea și cuantificarea unor compuşi biologic activi din specia Phyllanthus amarus, urmate de obținerea și caracterizarea unor nanoparticule de argint. Pentru identificarea și cuantificarea compușilor biologici s-au utilizat diferite metode, cum ar fi spectrofotometria UV-Vis și HPLC-UV-MS pentru analiza polifenolilor, LC-MS pentru analiza flavonelor metoxilate și a fitosterolilor. Dintre compușii identificați s-au cuantificat acidul p-cumaric, acidul ferulic, izocvercitrina, cvercitrina, rutozida, hispidulina, acacetina, casticina, stigmasterolul, beta-sitosterolul și campesterolul. În prezent, acesta este primul studiu prin care s-au identificat și cuantificat în Phyllanthus amarus hispidulina, casticina, acacetina și ergosterolul. În continuare, extractul a fost utilizat pentru obținerea de nanoparticule de argint (AgNPs), care au fost caracterizate prin spectroscopie UV-Vis, FTIR, TEM, EDX. De asemenea, au fost testate activitățile antimicrobiană şi antioxidantă a AgNPs. Rezultatele au confirmat faptul că Phyllantus amarus este o sursă de compuşi biologici care pot participa la obținerea de nanoparticule, cu potențial terapeutic.

Keywords: phenols, sterols, silver nanoparticles, antimicrobial, antioxidant

\section{Introduction}

Nanoparticles represent one of the great interest areas in the last decade, with applications in medicine, biology, electronics, etc. One of the methods used for obtaining nanoparticles is represented by the use of plant extracts, which is a cost-effective, non-toxic and eco-friendly method [36].

The Phyllanthus genus (Phyllanthaceae family) includes over 800 species of plants widespread in tropical and subtropical regions, including China and India [34]. Phyllanthus amarus has been used in traditional medicine for over 3,000 years for kidney, liver, urinary [31] and stomach disorders, asthma, bronchial infections, dropsy, jaundice [32], diabetes and intestinal parasites [31], chronic dysentery, gonorrhoea, pain [41]. Also, this plant is used for the treatment of different gynaecological disorders such as breast abscess, leucorrhoea and menorrhagia. [41].

The biologically active compounds highlighted in Phyllanthus amarus belong to the following categories: alkaloids, ellagitannins, lignans, volatile oil, triterpenes [32, 41], flavonoids, sterols [32]. 
FARMACIA, 2018, Vol. 66, 5

Phyllanthus amarus extracts exhibit numerous pharmacological activities: anti-amnesic [17], antioxidant [25], antinociceptive [16], anti-leptospiral [4], anticonvulsant [26], anti-inflammatory [21] and analgesic [15], antiulcer [38], anticancer [35], cardioprotective [34] and antimicrobial activity [32].

This paper proposes the identification and quantification of some phenolic and sterolic compounds from Phyllanthus amarus extract followed by the generation and characterization of silver nanoparticles obtained by green synthesis.

\section{Materials and Methods}

\section{Plant material and extraction method}

The analysed sample was purchased from retailers and was constituted of Phyllanthus amarus aerial parts finely pulverized. The extract was obtained by ultrasonication in methanol $(10 \% \mathrm{w} / \mathrm{v})$ for 10 minutes, and magnetic stirring for another 10 minutes, at room temperature followed by filtration.

Qualitative and quantitative characterization of Phyllanthus amarus extract

UV-Vis spectrophotometric methods were used for the determination of total flavonoid (TFC), total phenols (TPC) and total phenolic acids contents (TAC), using an Able Jasco V550 UV-Vis spectrophotometer (Japan). The total flavonoid content was quantified using the aluminium chloride colorimetric method [9], and the results were expressed as mg quercetin per gram of dried plant material (mg QE/g plant). The total phenolic acids content was determined by reaction with sodium nitrite and sodium molibdate in alkaline medium with formation of oximes [9], and the results were expressed as mg chlorogenic acid per gram dried plant material (mg CAE/g plant). The quantification of total phenols content was carried out using the Folin-Ciocâlteu method, and the results were expressed as $\mathrm{mg}$ gallic acid per gram of dried plant material (mg GAE/g plant) [9].

Determination of polyphenols, methoxylated flavonoids and phytosterols was performed by chromatographic methods. For separation, an Agilent 1100 HPLC series system (Agilent, USA) equipped with a binary pump, a degasser, an autosampler, a guard column and a thermostated column was used, while for detection, an UV detector and a MS detector were used.

According to Khalaf I et al. [20], the polyphenols content was determined by an RP-HPLC-UV-MS method. The following compounds were used as standards: caffeic, chlorogenic, p-coumaric acids and apigenin, fisetin, hyperoside, isoquercitrin, kaempferol, quercetin, quercitrin, myricetin, rutin from Sigma (Germany), ferulic, gentisic, sinapic acids and luteolin, patuletin from Roth (Germany) and caftaric acid from Dalton (USA).

The methoxylated flavonoids content was determined according to Mocan et al. [28] by a LC-MS method, using as standards: eupatilin and jaceosidin from ALB (Technology, China), acacetin, casticin, eupatorin and hispidulin from Sigma (Germany).

The quantification of phytosterols was performed by a LC-MS method [19], using as standards: brassicasterol, campesterol, ergosterol, $\beta$-sitosterol and stigmasterol from Sigma (Germany).

Synthesis and characterization of AgNPs

The synthesis of AgNPs was realized by mixing $1 \mathrm{~mL}$ plant extract with $10 \mathrm{~mL}$ of $5 \mathrm{mM}$ silver nitrate $\left(\mathrm{AgNO}_{3}\right)$ at $600 \mathrm{rpm}$ for approximately 1 hour at room temperature. AgNPs were separated by centrifugation at 10,000 rpm for 15 minutes. For purification, AgNPs were redispersed in water, followed by centrifugation, and the operation was repeated three times. The obtained AgNPs were dried in the oven and used for characterization.

The reduction of silver ion was firstly visually monitored and then by UV-Vis spectrophotometry in the 350 - $600 \mathrm{~nm}$ range, using a Jasco V 530 double beam UV-Vis spectrophotometer. For the determination of hydrodynamic diameter and zeta potential a Delsa Nano Submicron Particle Size Analyzer (Beckman Coulter, USA) was used. The morphology and size of AgNPs were determined using Transmission Electron Microscopy (TEM) with a Hitachi High-Tech HT7700 Transmission Electron Microscope (Japan). Energy dispersive X-ray analysis (EDX) was used to determine the most important elements constituting the chemical composition of AgNPs using an EDX system equipped with a Quanta 200 Environmental Scanning Electron Microscope (ESEM). FTIR analysis was performed with a Bruker Vertex 70 instrument (USA), in the range $4000 \mathrm{~cm}^{-1}$ to $310 \mathrm{~cm}^{-1}$.

Furthermore, AgNPs were tested for antibacterial and antioxidant activities, in comparison to those of the plant extract. Antibacterial activity was tested by the diffusion method [5] using Mueller-Hinton agar medium (Oxoid), and the microorganisms used were Staphylococcus aureus ATCC 25923 and Pseudomonas aeruginosa ATCC 27853. Ciprofloxacin ( $5 \mu \mathrm{g} / \mathrm{disc})$ was used as positive control. The antioxidant activity was determined by DPPH free radical scavenging assay [7, 40] and lipoxygenase inhibition assay [6].

\section{Results and Discussion}

Qualitative and quantitative characterization of extract The results indicate the presence of caffeic, chlorogenic, p-coumaric, ferulic and gentisic acids, quercitrin, isoquercitrin and rutoside in the analysed Phyllanthus amarus extract (Figure 1). These results are in line with literature data. Thus, among the identified polyphenolic compounds found in the literature, we mention hydroxybenzoic and hydroxycinnamic acid derivatives: $\beta$-glucogallin, geraniin, gallic acid, castalin; flavonols: quercetin, kaempferol and derivatives, rutin, myricetin, quercitrin; flavones: luteolin and derivatives; ellagic 
acid and derivatives; and other compounds like: quinic acid, brevifolin carboxylic acid, phloridzin, pinoresinol, ursolic acid [22]. Also, Kumar et al. reported the presence of corilagin, protocatechuic acid, p-coumaric acid, caffeic acid, syringin, 4-hydroxybenzoic acid; flavanone: prunin, eriodictyol, naringenin, gentisic acid and their derivatives, gallic acid, quinic acid, ferulic acid, chrysin, betulinic acid, oleanolic acid [23]. Also, Gunjan Guha et al. has mentioned the presence of caffeic acid, chlorogenic acid (caffeoylquinic acid), p-coumaric acid, isoquercitrin (quercetin-3-Oglucoside), rutin (quercetin-3-O-rutinoside) [10].
Berezi et al. identified and quantified gentisic acid (0.00006 $\mathrm{mg} \%)$, ferulic acid $(0.5958 \mathrm{mg} \%)$, caffeic acid (22.51 $\mathrm{mg} \%)$ and chlorogenic acid (9.23 $\mathrm{mg} \%)$ in an aqueous extract of Phyllanthus amarus [2]. Apigenin, caftaric acid, fisetin, hyperoside, luteolin, kaempferol, luteolin, myricetin, patuletin, quercetin and sinapic acid were not present in the analysed extract. Among the identified compounds, p-coumaric acid, ferulic acid, isoquercitrin, quercitrin, and rutoside were quantified (Table I).

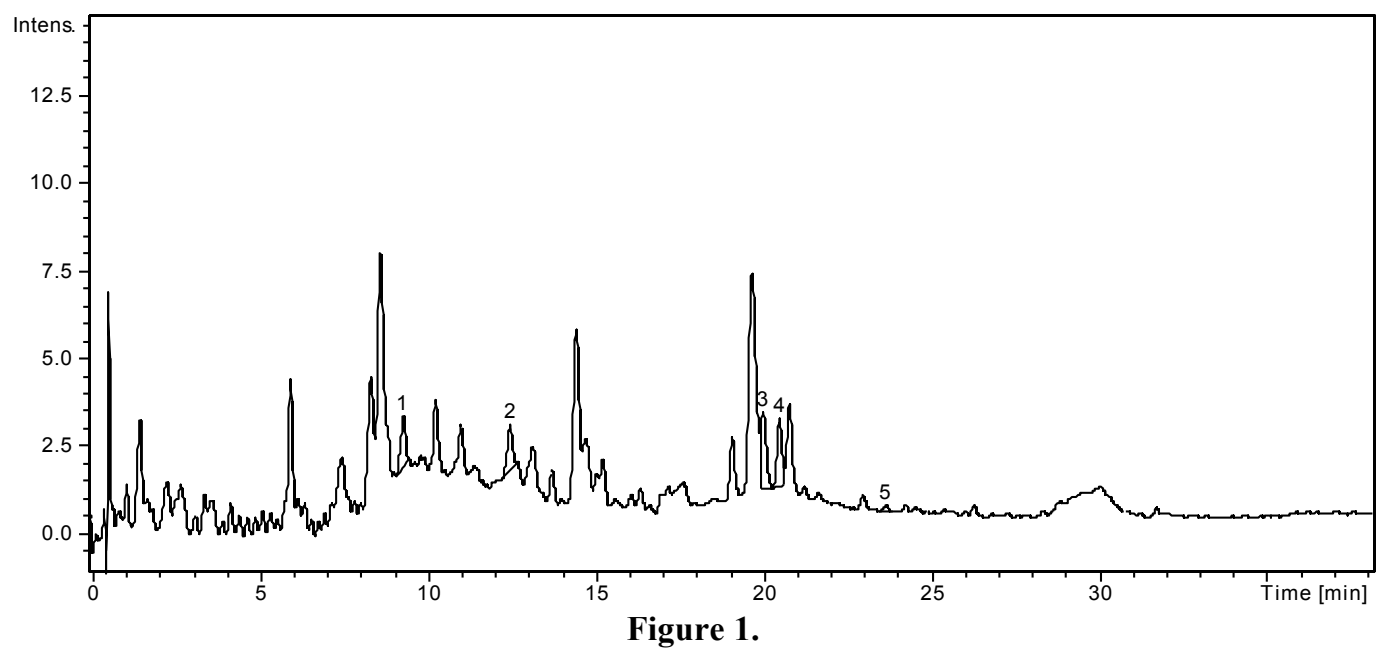

HPLC chromatogram of Phyllanthus amarus methanol extract: p-coumaric acid (1), ferulic acid (2), isoquercitrin (3), rutoside (4), quercitrin (5)

Table I

The concentration of phenolic compounds in Phyllanthus amarus ( $\mu \mathrm{g} / \mathrm{g}$ plant)

\begin{tabular}{|l|c|}
\hline \multicolumn{1}{|c|}{ Compound } & Concentration $(\mu \mathrm{g} / \mathrm{g}$ plant $)$ \\
\hline Caffeic acid & $*$ \\
\hline Caftaric acid & $*$ \\
\hline Chlorogenic acid & 8.62 \\
\hline p-coumaric acid & 7.09 \\
\hline Ferulic acid & - \\
\hline Fisetin & $*$ \\
\hline Gentisic acid & - \\
\hline Hyperoside & 37.41 \\
\hline Isoquercitrin & 3.65 \\
\hline Quercitrin & 29.35 \\
\hline Rutoside & \\
\hline
\end{tabular}

*compound present in sample (MS qualitative determination, UV signal $<$ limit of quantification)

Regarding the analysis of methoxylated flavonoids, the major compound in the Phyllanthus amarus extract was hispidulin, followed by acacetin and casticin (Table II). To the best of our knowledge, this is the first report of the identification and quantification of hispidulin, casticin, and acacetin in Phyllanthus amarus. Eupatilin, eupatorin, and jaceosidin were not present.
Table II

The concentration of methoxylated flavones in Phyllanthus amarus ( $\mu \mathrm{g} / \mathrm{g}$ plant)

\begin{tabular}{|l|c|}
\hline \multicolumn{1}{|c|}{ Compound } & Concentration $(\mu \mathrm{g} / \mathrm{g}$ plant $)$ \\
\hline Acacetin & 2.7396 \\
\hline Casticin & 0.3615 \\
\hline Hispidulin & 6.9216 \\
\hline
\end{tabular}

Hispidulin is 4',5,7-trihydroxy-6-methoxyflavone and proved antioxidant, anti-inflammatory, antifungal, antimutagenic and antineoplastic properties [33]. Acacetin, 5,7-dihydroxy-4'-methoxyflavone showed antiinflammatory/antinociceptive activity and can be used in the treatment of pain-related diseases [3]. Among casticin activities (3',5-dihydroxy-3,4',6,7-tetramethoxyflavone) cytotoxic and immunomodulatory properties are noted $[11,27]$.

Regarding the sterols category, the literature mentions, for Phyllanthus amarus, the existence of amarosterol A and B, stigmasterol [30], beta-sitosterol [43] and campesterol [30]. In agreement with the literature data, stigmasterol, beta-sitosterol and campesterol were identified and quantified in the analysed extract. Ergosterol was also found in small amounts in the Phyllanthus amarus extract (Table III). Brassicasterol was not present in the sample. 
FARMACIA, 2018, Vol. 66, 5

\section{Table III}

The concentration of phytosterols in Phyllanthus amarus ( $\mu \mathrm{g} / \mathrm{g}$ plant)

\begin{tabular}{|l|c|}
\hline \multicolumn{1}{|c|}{ Compound } & Concentration $(\mu \mathrm{g} / \mathrm{g}$ plant $)$ \\
\hline Stigmasterol & 87.28 \\
\hline$\beta$-Sitosterol & 568.04 \\
\hline Campesterol & 16.26 \\
\hline Ergosterol & 3.34 \\
\hline
\end{tabular}

The highest amount was obtained for $\beta$-sitosterol ( $24 \alpha$ ethyl-cholesterol), which shows anti-inflammatory and analgesic activities, hypocholesterolemic, antidiabetic, antioxidant, angiogenic effects, induces apoptosis and has genotoxic, immunomodulatory, chemoprotective and chemopreventive effects [37].

Literature also states that, among the three compounds mentioned, the most widespread is sitosterol, followed by campesterol and stigmasterol. In our case, sitosterol was followed by stigmasterol $(\Delta 22-24 \alpha$-ethylcholesterol), a compound with anti-inflammatory, anti-osteoarthritic, anti-hypercholesteraemic, cytotoxic, anti-tumour, anti-mutagenic and antioxidant activities

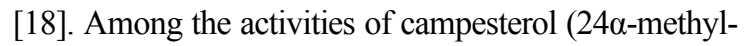
cholesterol), the reduction of carcinogen production, can be mentioned leading to the inhibition of cancer development [42].

The total phenols content in the plant sample was $5.17 \mathrm{mg} \mathrm{GAE} / \mathrm{g}$ plant, total flavonoids content 0.11 $\mathrm{mg} \mathrm{QE} / \mathrm{g}$ plant and total phenolic acids content was $0.14 \mathrm{mg} \mathrm{CAE} / \mathrm{g}$ plant.

The literature provides different values of the total phenolic content in Phyllanthus amarus: $21.3 \pm 3.6$ mg GAE/g dry extract [8], 171 15.6 mg GAE/g plant extract [24], $1083 \pm 66 \mathrm{mg}$ GAE/100 g plant material [25]. The values obtained by Kumaran et al. for total flavonoids content was $21.7 \pm 1.4 \mathrm{mg}$ rutin/g plant extract and for flavonols $18 \pm 2.4 \mathrm{mg}$ rutin/g plant extract [24].

Comparing the data obtained from the literature, it results that the chemical composition is influenced, among others, by the method of drying the plant, the extraction method and the extraction conditions used. Synthesis and characterization of AgNPs

AgNPs were synthesized by adding the vegetal extract to the silver nitrate solution, under continuous stirring; thus, the reduction of $\mathrm{Ag}^{+}$to $\mathrm{Ag}^{0}$ occurs. After the first 10 minutes of mixing the extract with silver nitrate, a colour change from yellow to brown was observed which turned dark-brown within 20 minutes. The mixture colour change is a general feature of the AgNPs synthesis [1].

The synthesis of AgNPs was monitored by recording the UV-Vis spectra of the extract, the $\mathrm{AgNO}_{3}$ solution, the initial mixture and the colloidal solution after 10, 20, 30 and 60 minutes (Figure 2).

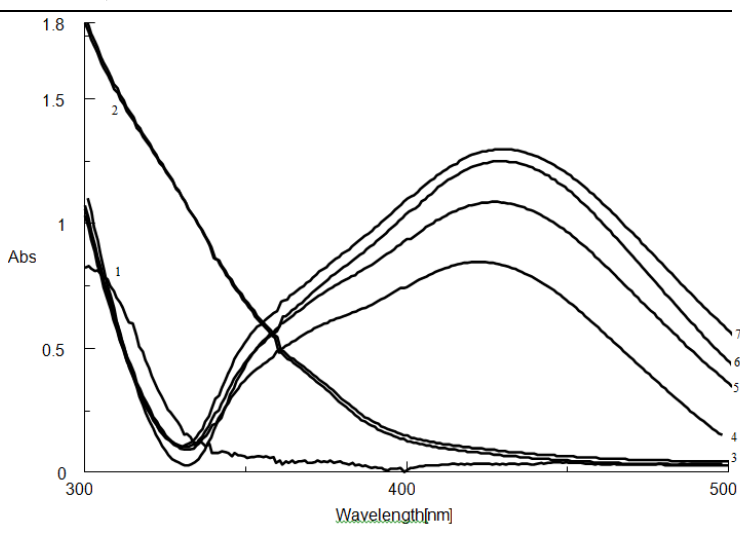

Figure 2.

$\mathrm{UV}-\mathrm{V}$ is spectra of the $\mathrm{AgNO}_{3}$ solution (1), the extract (2), the initial mixture (3) and of colloidal solution after 10 minutes (4), 20 minutes (5), 30 minutes (6) and 60 (7) minutes

On the extract, for AgNPs and initial mixture spectra no peak is observed in the $300-500 \mathrm{~nm}$ range. The peak can be observed on the colloidal solution spectra of the surface plasmon resonance band at $424 \mathrm{~nm}$, characteristic of AgNPs synthesis after 10 minutes, which demonstrates the start of the reduction process of $\mathrm{Ag}^{+}$. When the reaction time increases, a rise in absorbance can be observed. After 60' the peak remained unchanged, showing that the process was complete.

TEM method (Figure 3) was used to evaluate the shape and dimensions of AgNPs.

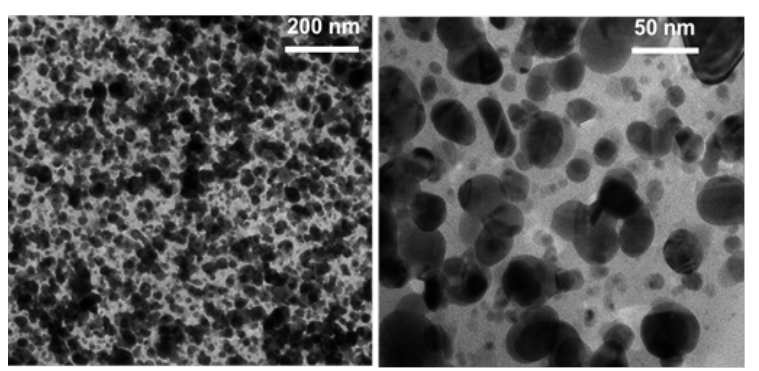

Figure 3.

TEM image of AgNPs

The AgNPs are spherical, uniform and show a slight degree of agglomeration probably due to the solvent evaporation during preparation [14]. The estimated size is $10-20 \mathrm{~nm}$. Also, AgNPs are surrounded by a thin layer of another material, which lies in the biomolecules that encapsulated the AgNPs and thus, prevented aggregation [14], playing, at the same time, the role of stabilizing agents [29].

The presence of biomolecules involved in the reduction of silver ion and the presence of elemental silver are also demonstrated by EDX (Figure 4). 


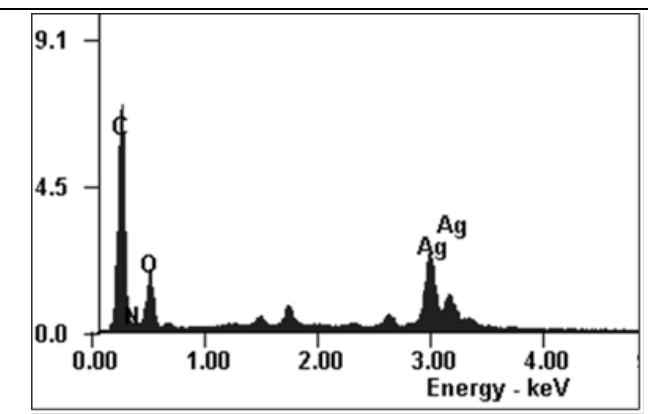

Figure 4.

EDX spectra of AgNPs
Thus, the specific peaks are observed for carbon, nitrogen and oxygen, suggesting the presence of biomolecules at the surface of AgNPs or in its proximity. The significant peak at $3 \mathrm{keV}$ is characteristic for elemental silver [13].

The size of AgNPs was confirmed by dynamic light scattering (DLS), the average size being $10 \mathrm{~nm}$, showing a very good correlation with the TEM results. Zeta potential of AgNPs (Figure 5) was -27.64 mV, demonstrating that the suspension is stable due to the capping biomolecules which by negative charges determine a rejection between nanoparticles [12].

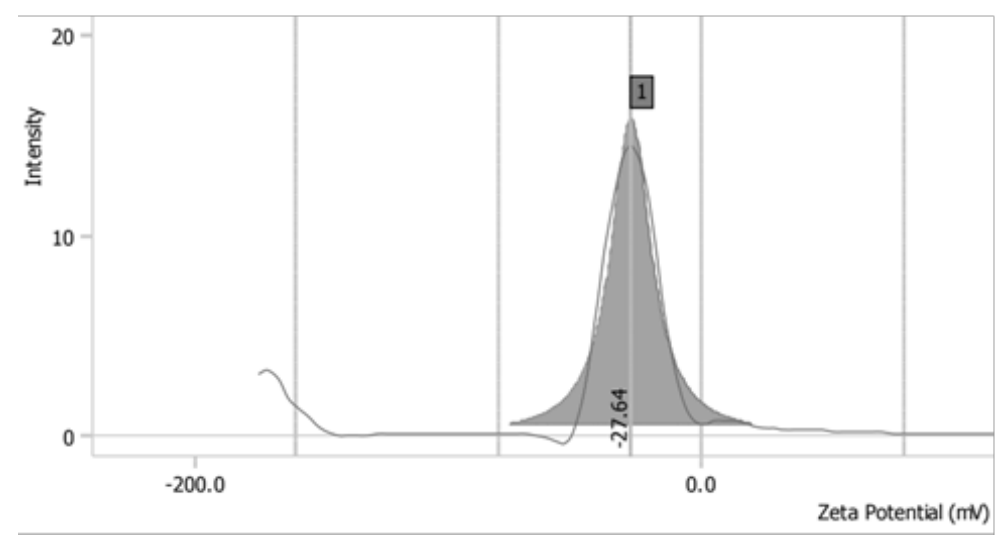

Figure 5.

Zeta potential of the AgNPs

By FTIR analysis, the functional groups responsible for the reduction and stabilization of AgNPs were studied by comparing the Phyllanthus amarus extract spectra and the synthesized silver nanoparticles spectra (Figure 6).

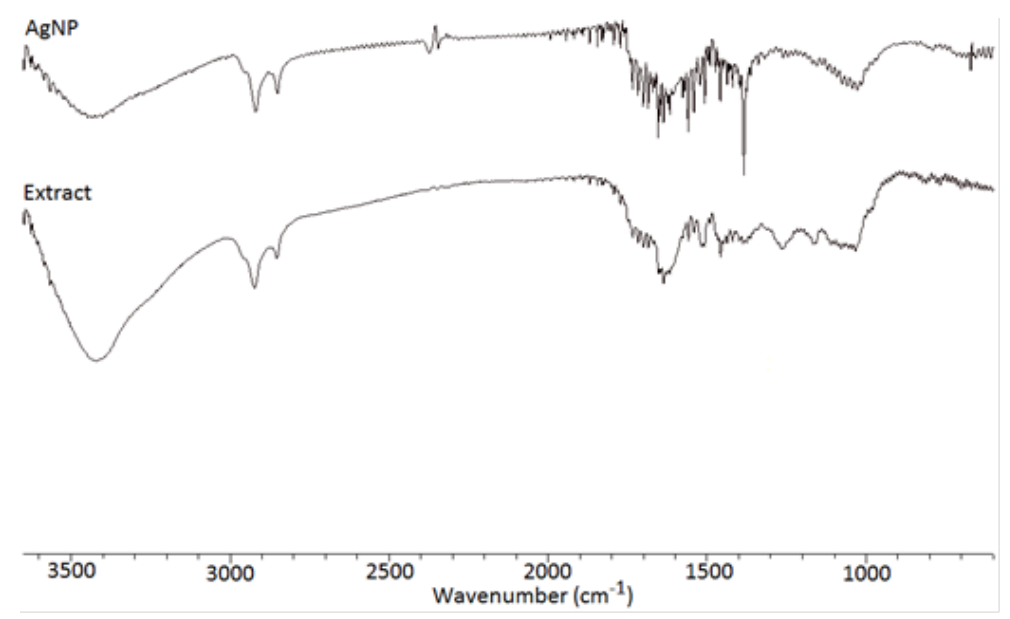

Figure 6.

Comparative FTIR spectra of Phyllanthus amarus extract and AgNPs

The comparative spectra show a shift in the next peaks: 3419 to $3435 \mathrm{~cm}^{-1}$ (OH stretching vibrations), 2923 to $2919 \mathrm{~cm}^{-1}$ and 2852 to $2850 \mathrm{~cm}^{-1}$ (alkyl C-H stretching vibrations bands), 1636 to $1653 \mathrm{~cm}^{-1}$ (stretching vibrations of $\mathrm{C}=\mathrm{C}$ absorption), 1448 to $1458 \mathrm{~cm}^{-1}$ (bending frequency for cyclic $\left(\mathrm{CH}_{2}\right) \mathrm{n}$ ), and bending $\mathrm{CH}$ vibrations of flavonoids), 1026 to $1028 \mathrm{~cm}^{-1}$ (cycloalkane). The peak from $1273 \mathrm{~cm}^{-1}$ (C-O single bonds stretching vibrations) in Phyllanthus extract spectra disappears in AgNPs spectra. Moreover, the appearance of a peak at $1383 \mathrm{~cm}^{-1}$ in AgNPs spectra may be interpreted as an attachment, during the synthesis, of some $-\mathrm{CH}_{2}\left(\mathrm{CH}_{3}\right)$ groups on the surface of AgNPs. Thus, the biomolecules responsible for 
FARMACIA, 2018, Vol. 66, 5

obtaining AgNPs may belong to phenols and sterols classes.

The antibacterial activity of the synthesized AgNPs compared to that of Phyllanthus amarus extract was investigated on both Gram-positive bacterium $S$. aureus and Gram-negative bacterium P. aeruginosa. The diameter of the inhibition zones $(\mathrm{mm})$ is shown in Table IV.

The extract exhibits antibacterial activity only against Gram-positive bacteria, while AgNPs show activity against both Gram-positive and Gram-negative bacteria,

the effect on $S$. aureus being higher in comparison with the extract. The antibacterial activity of AgNPs can be explained by several mechanisms, including bacteria attachment to the wall or release of silver ions from AgNPs and interaction with thiol groups from the respiratory enzymes of bacterial cells [39]. The antioxidant activity of the Phyllanthus amarus extract and of the synthesized AgNPs was evaluated using DPPH free radical scavenging assay and lipoxygenase inhibition assay, the results expressed as $\mathrm{IC}_{50}$ values being presented in Table IV.

Table IV

Antibacterial and antioxidant activities of Phyllanthus amarus extract and AgNPs

\begin{tabular}{|c|c|c|c|c|}
\hline \multirow{2}{*}{ Sample } & \multicolumn{2}{|c|}{$\begin{array}{c}\text { Antibacterial activity } \\
\text { The diameter of inhibition zones (mm) }\end{array}$} & \multicolumn{2}{c|}{ Antioxidant activity } \\
\cline { 2 - 5 } & S. aureus & P. aeruginosa & $\begin{array}{c}\text { DPPH free radical } \\
\text { scavenging assay }\end{array}$ & $\begin{array}{c}\text { Lipoxygenase } \\
\text { inhibition assay }\end{array}$ \\
\hline Phyllanthus amarus extract & $10 \pm 0$ & 0 & $12.68 \pm 0.01 \mathrm{mg} / \mathrm{mL}$ & - \\
\hline AgNPs & $15 \pm 0$ & $14 \pm 0.5$ & - & $3.82 \pm 0.07 \mu \mathrm{g} / \mathrm{mL}$ \\
\hline
\end{tabular}

It can be noticed that in the case of AgNPs the $\mathrm{IC}_{50}$ value cannot be calculated for the DPPH free radical scavenging assay, while in the case of the lipoxygenase inhibition assay $\mathrm{IC}_{50}$ is $3.82 \pm 0.07 \mu \mathrm{g} / \mathrm{mL}$. This fact could be explained by the different mechanisms of antioxidant activity. Thus, in the DPPH free radical scavenging assay, the 2,2-diphenyl-1-picrylhydrazyl radical requires compounds with hydroxyl groups (or other hydrogen donor groups), which contributed to the production of AgNPs, while, in the case of lipoxygenase inhibition assay, the AgNPs lipoxygenase inhibitory effect can be explained by the high dimensions of silver nanoparticles encapsulated by biomolecules, preventing in this way the access of the substrate to the active centre of the enzyme. On the other hand, these nanoparticles could modify the three-dimensional structure of the enzyme or the three-dimensional structure of its active site.

\section{Conclusions}

Phyllanthus amarus is a medicinal plant widely used due to its properties in the traditional medicine. The phytochemical analysis of Phyllanthus amarus led to the identification of phenolic acids such as caffeic acid, chlorogenic acid, p-coumaric acid, ferulic acid, gentisic acid, flavones like quercitrin, isoquercitrin, rutoside, methoxylated flavonoids like hispidulin, acacetin, and casticin. Also, other secondary metabolites, like phytosterols (ergosterol, stigmasterol, betasitosterol, and campesterol) were determined. To the best of our knowledge, some of these compounds were identified and quantified for the first time: hispidulin, acacetin, casticin, and ergosterol.

Moreover, our study shows a simple, fast and ecofriendly method for obtaining AgNPs. In this process, the above-mentioned quantified compounds can participate and can also act as stabilizers. The characterization of AgNPs was performed by various analysis methods.

This study showed that Phyllanthus amarus is a source of bioactive compounds that can be used in the AgNPs generation, which represents a valid argument for future research.

\section{References}

1. Ali A, Zafar H, Zia M, Ul Haq I, Phull AR, Ali JS, Hussain A, Synthesis, characterization, applications, and challenges of iron oxide nanoparticles. Nanotechnol Sci Appl., 2016; 19(9): 49-67.

2. Berezi EP, Uwakwe AA, Monago-Ighorodje CC, Nwauche KT, Gastroprotective potentials of aqueous leaf extracts of Phyllanthus amarus on ibuprofeninduced ulcer in Wistar rats. Int J Adv Res Biol Sci., 2017; 4(10): 138-146.

3. Carballo-Villalobos AI, González-Trujano ME, LópezMuñoz FJ, Evidence of mechanism of action of anti-inflammatory/antinociceptive activities of acacetin. Eur J Pain., 2014; 18(3): 396-405.

4. Chandan S, Umesha S, Balamurugan V, Anti leptospiral antioxidant and DNA damaging properties of Eclipta alba and Phyllanthus amarus. Sci Rep., 2012; 1(4): $1-8$.

5. Clinical and Laboratory Standard Institute, Performance standards for antimicrobial susceptibility testing, $27^{\text {th }}$ ed. Supplement M100, Wayne, USA, 2017.

6. Corciova A, Ciobanu C, Poiata A, Nicolescu A, Drobota M, Varganici CD, Pinteala T, Fifere A, Marangoci N, Mircea $C$, Inclusion complexes of hesperidin with hydroxypropyl-beta-cyclodextrin physico-chemical characterization and biological assessment. Dig J Nanomater Biostruct., 2014; 9(4): 1623-1637.

7. Drăgan M, Stan CD, Pânzariu A, Profire L, Evaluation of anti-inflammatory potential of some new ferullic acid derivatives. Farmacia, 2016; 64(2): 194-197.

8. Eldeen IMS, Seow EM, Abdullah R, Sulaiman SF, In vitro antibacterial, antioxidant, total phenolic contents and anti-HIV-1 reverse transcriptase activities of 
FARMACIA, 2018, Vol. 66, 5

extracts of seven Phyllanthus sp. S Afr J Bot., 2011; 77: 75-79.

9. Gird CE, Nencu I, Popescu ML, Costea T, Duţu LE, Balaci TD, Olaru OT, Chemical, antioxidant and toxicity evaluation of rosemary leaves and its dry extract. Farmacia, 2017; 65(6): 978-983.

10. Guha G, Rajkumar V, Ashok Kumar R, Mathew L, Aqueous extract of Phyllanthus amarus inhibits chromium(VI)-induced toxicity in MDA-MB-435S cells. Food Chem Toxicol., 2010; 48: 396-401.

11. Haidara K, Zamir L, Shi QW, Batist G, The flavonoid casticin has multiple mechanisms of tumor cytotoxicity action. Cancer Lett., 2006; 242: 180-190.

12. Haider MJ, Mehdi MS, Study of morphology and zeta potential analyzer for the silver nanoparticles. Int J Sci Eng Res., 2014; 5(7): 381-387.

13. Haytham MMI, Green synthesis and characterization of silver nanoparticles using banana peel extract and their antimicrobial activity against representative microorganisms. J Radiat Res Appl Sci., 2015; 8(3): 265-275.

14. He Y, Wei F, Ma Z, Zhang H, Yang Q, Yao B, Huang Z, Li J, Zeng C, Zhang Q, Green synthesis of silver nanoparticles using seed extract of Alpinia katsumadai, and their antioxidant, cytotoxicity, and antibacterial activities. RSC Adv., 2017; 7: 3984239851.

15. Iranloye BO, Owoyele VB, Kelani OR, Olaleye $\mathrm{SB}$, Analgesic activity of aqueous leaf extracts of Phyllanthus amarus. Afr J Med Med Sci., 2011; 40: 47-50.

16. Itoro E, Ukana D, Ekaete D, Phytochemical screening and nutrient analysis of Phyllanthus amarus. Asian J Plant Sci Res., 2013; 3: 116-122.

17. Joshi H Parle, Pharmacological evidence for antiamnesic potentials of Phyllanthus amarus in mice. Afr J Biomed Res., 2007; 10: 165-173.

18. Kaur N, Chaudhary J, Jain A, Kishore L, Stigmasterol: a comprehensive review. Int J Pharm Sci Res., 2011; 2(9): 2259-2265.

19. Khalaf I, Corciova A, Vlase L, Ivanescu B, Lazar D, LC/MS analysis of sterolic compounds from Glycyrrhiza glabra. Studia UBB Chemia, 2011; 56(3): 97-102.

20. Khalaf I, Vlase L, Lazăr D, Corciovă A, Ivănescu M, Lazar MI, HPLC-UV-MS study of polyphenols from Glycyrrhiza glabra. Farmacia, 2010; 58(4): 416-421.

21. Kiemer AK, Hartung T, Huber C, Vollmar AM, Phyllanthus amarus has anti-inflammatory potential by inhibition of iNOS, COX-2 and cytokines via the NF-кB pathway. J Hepatol., 2003; 38(3): 289-297.

22. Kumar S, Chandra P, Bajpai V, Singh A, Srivastava M, Mishrad DK, Kumar B, Rapid qualitative and quantitative analysis of bioactive compounds from Phyllanthus amarus using LC/MS/MS techniques. Ind Crops Prod., 2015; 69: 143-152.

23. Kumar S, Singh A, Kumar B, Identification and characterization of phenolics and terpenoids from ethanolic extracts of Phyllanthus species by HPLCESI-QTOF-MS/MS. J Pharm Anal., 2017; 7: 214 222.

24. Kumaran A, Karunakaran RJ, In vitro antioxidant activities of methanol extracts of five Phyllanthus species from India. LWT-Food Sci Technol., 2007; 40(2): 344-352.
25. Lim YY, Murtijaya J, Antioxidant properties of Phyllanthus amarus extracts as affected by different drying methods. LWT-Food Sci Technol., 2007; 40(9): 1664-1669.

26. Manikkoth S, Deepa B, Joy AE, Rao S, Anticonvulsant activity of Phyllanthus amarus in experimental animal models. Int J Appl Biol Pharm Technol., 2011; 4: 144-149.

27. Mesaik MA, Azizuddin, Murad S, Khan KM, Tareen RB, Ahmed A, Atta-ur-Rahman, Choudhary MI, Isolation and immunomodulatory properties of a flavonoid, casticin from Vitex agnus-castus. Phytother Res., 2009; 23(11): 1516-1520.

28. Mocan A, Crisan G, Vlase L, Ivanescu B, Badarau AS, Arsene AL, Phytochemical investigations on four Galium species from Romania. Farmacia, 2016; 64(1): 95-99.

29. Moldovan B, David L, Achim M, Clichici S, Filip GA, A green approach to phytomediated synthesis of silver nanoparticles using Sambucus nigra L. fruits extract and their antioxidant activity. J Mol Liq., 2016; 221: 271-278.

30. Nahar L, Sarker SD, Delazar A, Phytochemistry of genus Phyllanthus. In book: Phyllanthus species: scientific evaluation and medicinal applications, CRC Press, Editors: Kuttan R, Harikumar KB, Taylor \& Francis Group, 2012: 119-139.

31. Okwute Simon K, Okolo Simon C, Okoh-Esene R, Olajide Olutayo O, Biological and chemical evaluation of the extracts of the leaf of Phyllanthus amarus Schum. Int J ChemTech Res., 2014; 7(5): 2347-2354.

32. Patel JR, Tripathi P, Sharma V, Chauhan NS, Dixit VK, Phyllanthus amarus: ethnomedicinal uses, phytochemistry and pharmacology: a review. $J$ Ethnopharmacol., 2011; 138: 286-313.

33. Patel K, Patel DK, Medicinal importance, pharmacological activities, and analytical aspects of hispidulin: a concise report. $J$ Tradit Complement Med., 2016; 7(3): 360-366.

34. Putakala M, Gujjala S, Nukala S, Bongu SBR, Chintakunta N, Desireddy S, Cardioprotective effect of Phyllanthus amarus against high fructose diet induced myocardial and aortic stress in rat model. Biomed Pharmacother., 2017; 95: 1359-1368.

35. Rajeshkumar NV, Joy KL, Kuttan G, Ramsewak RS, Nair MG, Antitumour and anticarcinogenic activity of Phyllanthus amarus extract. J Ethnopharmacol., 2002; 81(1): 17-22.

36. Rao B, Tang RC, Green synthesis of silver nanoparticles with antibacterial activities using aqueous Eriobotrya japonica leaf extract. Adv Nat Sci: Nanosci Nanotechnol., 2017; 8: 015014.

37. Saeidnia S, Manayi A, Gohari AR, Abdollahi M, The story of beta-sitosterol - a Review. Eur J Med Plants, 2014; 4(5): 590-609.

38. Shokunbi OS, Odetola AA, Gastroprotective and antioxidant activities of Phyllanthus amarus extracts on absolute ethanol-induced ulcer in albino rats. $J$ Med Plants Res., 2008; 2: 261-267.

39. Sun Q, Cai X, Li J, Zheng M, Chen Z, Yu CP, Green synthesis of silver nanoparticles using tea leaf extract and evaluation of their stability and antibacterial activity. Colloids Surf A Physicochem Eng Asp., 2014; 44(5): 226-231. 
FARMACIA, 2018, Vol. 66, 5

40. Tataringa G, Stan C, Mircea C, Jitareanu A, Zbancioc AM, Antioxidant evaluation of some coumarin derivatives. Farmacia, 2016; 64(4): 533-538.

41. Verma S, Sharma H, Garg M, Phyllanthus Amarus: a review. J Pharmacogn Phytochem., 2014; 3(2): 18-22.

42. Woyengo TA, Ramprasath VR, Jones PJH, Anticancer effects of phytosterols. Eur J Clin Nutr., 2009; 63: 813-820.
43. Yuandani IJ, Menaga I, Khairana H, Kok MC, Inhibitory effects of compounds from Phyllanthus amarus on nitric oxide production, lymphocyte proliferation, and cytokine release from phagocytes. Drug Des Devel Ther., 2016; 10: 1935-1945. 